\title{
Relação médico-paciente na assistência em contexto pandêmico: responsabilidades e vulnerabilidades dos sujeitos
}

Doctor-patient relationship in care in a pandemic context: responsibilities and vulnerabilities of the subjects

Relación médico-paciente en la atención en un contexto pandémico: responsabilidades y vulnerabilidades de los sujetos

Camila Vasconcelos ${ }^{1}$

Elda Coelho de Azevedo Bussinguer ${ }^{2}$

\section{Resumo}

A despeito dos papéis de fortes e inatingíveis, habitualmente desempenhados por médicos, e de frágeis e vulneráveis pelos pacientes nas relações assistenciais no contexto pandêmico do coronavírus, denominado SARS-CoV-2 e causador da COVID-19, os cenários de susceptibilidade de ambos passaram a se apresentar-, cada qual com sua peculiaridade, desnudando as dores e considerando a perspectiva de humanização dos cuidadores cientistas. A partir dessa conjuntura, este escrito objetivou discorrer a respeito da relação médico-paciente na assistência em contexto pandêmico, pressupondo a modificação - ainda que temporária - de seu perfil, bem como dos pontos de vista das responsabilidades e vulnerabilidades dos seus sujeitos segundo teorizações, princípios e normas (bio)éticojurídicas. Optou-se pela escrita teórico-filosófica, nos moldes metodológicos de uma pesquisa analítica. A análise mostrou-se favorável à percepção das possibilidades de aproximações e distanciamentos entre médicos e pacientes no decurso da pandemia, seja pela via da comunicação presencial, com o acréscimo de recomendações e protocolos aos profissionais de saúde, a exemplo do protocolo Spikes - substancialmente utilizado nos centros de saúde brasileiros -, seja por meio da telemedicina, enquanto significativo recurso em vista do distanciamento social, também na assistência. Considerou-se elementos como a falibilidade da ciência e a percepção da vulnerabilidade dos médicos, capazes de sentir dor, estafa e frustração. Compreendeu-se pela possibilidade de simetralização da relação médico-paciente a partir da humanização, não somente do atendimento assistencial, mas da imagem do profissional de saúde, antes endeusado, embora tenha sido mantida a expectativa e admiração social.

\section{Palavras-chave}

Relações Médico-Paciente. Vulnerabilidade em Saúde. Pandemias. Telemedicina.

\section{Abstract}

Despite the roles of strong and unattainable, usually played by physicians, and fragile and vulnerable by patients in care relations in the coronavirus pandemic context, called SARSCoV-2 and causing COVID-19, the susceptibility scenarios of both have passed to present

\footnotetext{
${ }^{1}$ Doutora em Bioética pela Universidade de Brasília, Brasília, DF, Brasil; professora no eixo Ético-Humanístico, Faculdade de Medicina, Universidade Federal da Bahia, Salvador, Bahia, Brasil. https://orcid.org/0000-0003-0847-0990. E-mail: camila.vasconcelos@ufba.br

2 Pós-Doutora em Saúde Coletiva, Universidade Federal do Rio de Janeiro, Rio de Janeiro, RJ, Brasil; Doutora em Bioética, Universidade de Brasília, Brasília, DF, Brasil; coordenadora, Programa de Pós-Graduação em Direitos e Garantias Fundamentais, Faculdade de Direito de Vitória (FDV), Vitória, Espírito Santo, Brasil. https://orcid.org/0000-0003-4303-4211. E-mail: elda.cab@gmail.com
} 


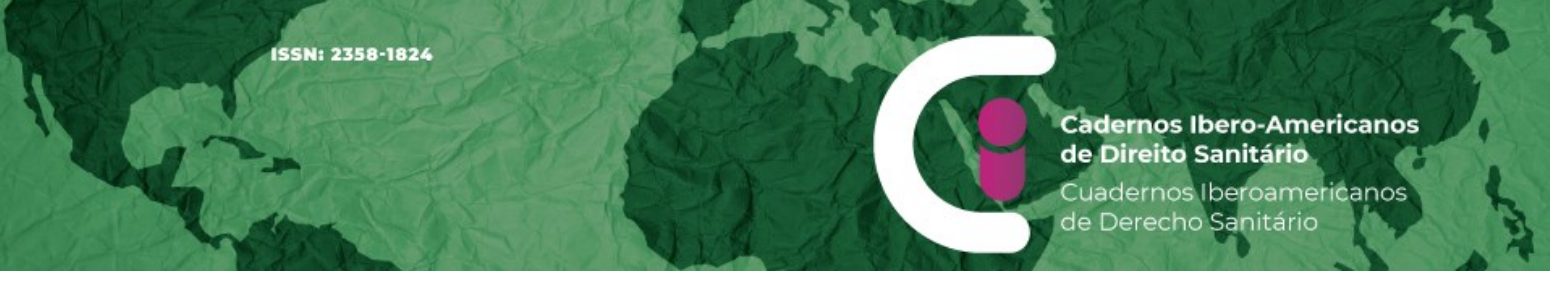

themselves, each with its own peculiarity, laying bare the pain and considering the perspective of humanization of the scientific caregivers. From this juncture, this writing aimed to discuss the doctor-patient relationship in care in a pandemic context, assuming the modification - albeit temporary - of its profile, as well as the points of view of the responsibilities and vulnerabilities of its subjects according to theorizations, (bio)ethical-legal principles and norms. We opted for the theoretical-philosophical writing, in the methodological molds of an analytical research. The analysis was favorable to the perception of the possibilities of approximations and distances between physicians and patients during the pandemic, either through face-to-face communication, with the addition of recommendations and protocols to health professionals, such as the Spikes protocol - substantially used in Brazilian health centers - either through telemedicine, as a significant resource in view of the social distance, also in care. Elements such as the fallibility of science and the perception of vulnerability of physicians, capable of feeling pain, fatigue and frustration, were considered. It was understood by the possibility of symmetry of the doctor-patient relationship from the humanization, not only of the assistance service, but of the image of the health professional, previously deified, although the expectation and social admiration was maintained.

\section{Keywords}

Physician-Patient Relations. Health Vulnerability. Pandemics. Telemedicine.

\section{Resumen}

A pesar de los roles de fuerte e inalcanzable, generalmente desempeñado por los médicos, y frágil y vulnerable de los pacientes en las relaciones de atención en el contexto de la pandemia de coronavirus, llamado SARS-CoV-2 y causante de COVID-19, los escenarios de susceptibilidad de ambos han pasado a presentarse, cada uno con su peculiaridad, poniendo al descubierto los dolores y considerando la perspectiva de humanización de los cuidadores científicos. Desde esta coyuntura, este escrito tuvo como objetivo discutir la relación médico-paciente en la atención en un contexto pandémico, asumiendo la modificación --aunque temporal-- de su perfil, así como los puntos de vista de las responsabilidades y vulnerabilidades de sus sujetos según las teorizaciones. , principios y normas (bio) ético-legales. Optamos por la escritura teórico-filosófica, en los moldes metodológicos de una investigación analítica. El análisis fue favorable a la percepción de las posibilidades de aproximaciones y distancias entre médicos y pacientes durante la pandemia, ya sea a través de la comunicación presencial, con la incorporación de recomendaciones y protocolos a los profesionales de la salud, como el protocolo de Spikes - sustancialmente utilizado en los centros de salud brasileños, ya sea a través de la telemedicina, como recurso significativo ante la distancia social, también en la atención. Se consideraron elementos como la falibilidad de la ciencia y la percepción de vulnerabilidad de los médicos, capaces de sentir dolor, fatiga y frustración. Se entendió por la posibilidad de simetría de la relación médico-paciente desde la humanización, no solo del servicio asistencial, sino de la imagen del profesional de la salud, previamente deificada, aunque se mantuvo la expectativa y admiración social.

\section{Palabras clave}

Relación Médico-Paciente. Vulnerabilidad en Salud. Pandemias. Telemedicina.

\section{Introdução}

Ao longo das últimas décadas as imagens de médicos e pacientes permearam o imaginário popular como, respectivamente, pessoas capazes de enfrentar terríveis ameaças 
à saúde e pessoas sobre as quais as curas poderiam realizar-se, sob a proteção dos primeiros, aguerridos conhecedores da arte de cuidar e da ciência. Habitualmente, os pacientes ocupavam o lugar de frágeis e vulneráveis, e os médicos o lugar de fortes e inatingíveis.

Construía-se, sob esse ponto de vista, a noção da relação médico-paciente como composta tanto pelo poderoso e desempoderado, inabalável e vulnerável, ou seja, uma compreensão idônea à percepção de assimetria na relação tendo em vista o conhecimento científico, em ocultação da ideia de médicos enquanto humanos, ou seja, também susceptíveis à dor, ao receio, ou à constatação de falibilidade de sua ciência, o que agora então se observa, sobretudo diante do que a natureza foi capaz de apresentar, em larga escala.

Isto porque, advindo o contexto pandêmico do coronavírus denominado SARS-CoV2, causador da doença COVID-19, surgido ao início de 2020 em proporção global, os cenários de susceptibilidade de ambos os sujeitos - médicos e pacientes -, passaram a apresentar-se, cada qual com sua peculiaridade, desnudando-se as dores e considerandose a perspectiva de humanização dos cuidadores cientistas.

É a partir dessa conjuntura que este escrito discorre a respeito da relação médicopaciente na assistência em contexto pandêmico, pressupondo a modificação - ainda que temporária - do perfil dessa relação e dos pontos de vista das responsabilidades e vulnerabilidades dos seus sujeitos, segundo teorizações, princípios e normas (bio)éticojurídicas.

\section{(As)simetria na relação: vulnerabilidade e ciência (in)falível}

Para compreensão do que se pretende aqui analisar, importante se faz relembrar que o termo vulnus em latim significa ferida, e está presente na origem da palavra vulnerabilidade que, por sua vez, denota a susceptibilidade de ser ferido, magoado. Essa ferida, que, em termos simbólicos, evoca a ideia de sofrimento, pode estar ligada a uma ação recebida por um sujeito exposto a circunstâncias de passividade. Somado a isso, a circunstância de doença, situada no sentido característico da vulnerabilidade, traz ao paciente a condição de fragilidade, especialmente na medida em que se tem a percepção da doença como uma cidadania mais onerosa (1), ou como um instrumento da vida que obriga o sujeito ao reconhecimento de sua finitude (2). 
Conceitualmente, ao abordar os sentidos da vulnerabilidade no discurso bioético, Patrão Neves (3) os distingue em três, sendo eles o de característica (adjetivo), de condição (substantivo) e de princípio. Inicialmente a autora ressalta a função adjetivante da vulnerabilidade, que afirma estar presente no vocabulário ético-normativo de documentos internacionais, explicando que os documentos utilizam a sua acepção essencialmente como característica, ao classificar indivíduos ou grupos que necessitam de proteção (3).

Destacando a modificação no entendimento da noção de vulnerabilidade a partir da visão europeia ocidental, Patrão Neves apresenta o sentido de vulnerabilidade como condição ou realidade constitutiva humana, portanto, inalienável e irredutível (3), ainda que presente a autonomia do sujeito e o reforço desta. A autora inclui, nessa reflexão, as noções de subjetividade - como exposição de um sujeito a outro - e responsabilidade - como dever de resposta solidária ao outro que se expõe -, conceitos esses sob as perspectivas dos filósofos Emmanuel Lévinas e Hans Jonas, respectivamente (3).

Em relação ao terceiro sentido de princípio, Patrão Neves (3) compreende a vulnerabilidade como uma confluência dos sentidos de condição e característica, presentes na Declaração Universal sobre Bioética e Direito Humanos (DUBDH) (4). O sentido de princípio traz tanto a determinação de respeito pela vulnerabilidade e pela integridade, exprimindo o respeito pela condição humana vulnerável, quanto a busca pela proteção de sujeitos ou grupos na medida em que há a vulnerabilidade em circunstâncias especiais, como características:

o princípio da vulnerabilidade interpela diretamente o profissional de saúde na sua responsabilidade de estabelecer relações simétricas com a pessoa doente e obriga as instituições a proteger, a zelar por todos os cidadãos igualmente, mesmo quando estes não têm poder de reivindicação. (3)

Observa-se, ainda, uma quarta acepção do termo, que por meio de significativo esforço acadêmico e político, passou a ser considerado na elaboração da DUBDH em atenção às diversidades socioeconômicas e contextuais dos povos de países em desenvolvimento: a vulnerabilidade social.

Esta, que traz consigo forte perspectiva bioética latino-americana, é discutida por Lorenzo (5) como fato social significativo a ser considerado para a proteção de indivíduos e comunidades em países em desenvolvimento. O autor considera circunstâncias que influenciam fortemente para a ocorrência da situação de vulnerabilidade social e que interferem na autodeterminação dos sujeitos, apontando a debilidade do nível de instrução, 
a disparidade social e a exclusão da assistência à saúde como significativas (6). Tais circunstâncias requerem a implementação de medidas sociopolíticas com vistas a melhorar a capacidade de vigilância e regulação (5).

Segundo Garrafa e Prado, a vulnerabilidade social tem seu significado voltado ao contexto de desproteção, desamparo e desfavorecimento de populações que vivem a exclusão social no que se refere aos avanços e benefícios advindos do desenvolvimento mundial (6). Essa é a perspectiva sobre vulnerabilidade que prepondera no contexto latinoamericano, tal como assinala Correa, que aponta o seu conceito para a ideia de dependência que impede ou ameaça de autodeterminação e a liberdade de escolha dos sujeitos acerca dos seus ideais de vida e desenvolvimento (7).

Para a análise da vulnerabilidade social, Correa propõe também dois níveis de apreciação: o primeiro relativo à condição humana de fragilidade, que limita a liberdade, possibilitando o acontecimento da enfermidade e a própria finitude; e o segundo relativo à ausência do que considera o básico para as necessidades humanas, implicando em pobreza ou falta de saúde, presente em diversas situações da América Latina (7).

A respeito da condição humana e sua vulnerabilidade inerente, percebe-se que Correa introduz o conceito de liberdade como elemento que se restringe, na medida em que a fragilidade do sujeito se apresenta (7). Observa-se que essa ponderação sobre a liberdade propõe uma questão sobre a possibilidade ou a impossibilidade da presença concomitante da vulnerabilidade e da autonomia do sujeito em um mesmo contexto. Isto porque, segundo a perspectiva do filósofo Immanuel Kant, a liberdade está inseparavelmente ligada ao conceito de autonomia (8) e, na medida em que Kant afirma não ser livre o sujeito que é vulnerável na ação, não seria também autônomo.

Entretanto, para Patrão Neves (3), o sentido de condição inerente ao humano da vulnerabilidade a torna irredutível e inalienável, de maneira que, mesmo presente a autonomia do sujeito, esta não possui a capacidade de se anular. A autora explica: "Por isso não pode ser ultrapassada ou eliminada e o reforço da autonomia, ao lado da crescente exigência de consentimento são, não obstante, inexoravelmente insuficientes para neutralizar os prejuízos a que cada vulnerabilidade se encontra exposta" (3).

Segundo essa visão, mantém-se a importância do cuidado para com a subjetividade do indivíduo em qualquer circunstância, não cabendo o descuido nas relações em saúde sob o argumento desse indivíduo ser autônomo. Essa ideia coaduna com a defesa de Anjos 


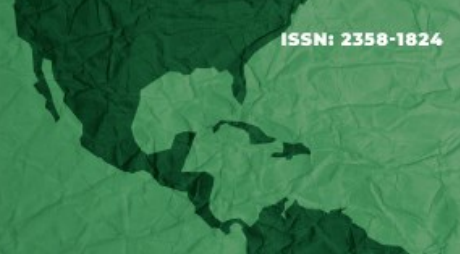

(9), que apresenta a ideia de uma necessária parceria entre vulnerabilidade e autonomia em saúde.

Discutindo sobre a postura moderna e criticando o enaltecimento da autonomia em detrimento do contínuo cuidado em relação à vulnerabilidade, Kemp e Rendtorff também discorrem sobre a questão:

\begin{abstract}
Ora, se o dever do respeito pela vulnerabilidade dos seres foi muitas vezes esquecido no passado, tal deveu-se, até à atualidade, ao fato de a idéia de autonomia ter predominado na ética dos sistemas de saúde modernos. Acreditou-se que, uma vez preservada e respeitada a autonomia do doente, depois de garantir, por exemplo, o seu consentimento esclarecido, o médico e o restante pessoal já não tinham outras medidas de precaução a tomar para proteger o doente. (10)
\end{abstract}

Tal aspecto trazido pelos autores coaduna com a crítica à postura contratual e mercantilista de exercício das relações em saúde, em que o respeito à autonomia é confundido com o cumprimento de protocolos documentais. Essa postura abandona subjetivamente o paciente em um território que não lhe é afeito, sob o argumento de manutenção de reforços legais para o exercício de sua vontade. Na medida em que implica na redução do respeito à fragilidade humana e seu devido cuidado nas relações em saúde, rechaça-se erroneamente o reconhecimento da vulnerabilidade e o respeito pela dignidade e integridade dos sujeitos.

Segundo Renaud, a vulnerabilidade traz a noção de "receptividade não susceptível de ser inteiramente transformada em aç̧ão" (11), ou seja, a sujeição de alguém não capaz de agir em resposta à agressão recebida. Traz, ainda, a possibilidade de pensar-se como recíproca da potencialidade (11), o que confere, também, a essa reflexão, a busca pelo conceito de poder nas relações humanas. Portanto, ter-se-ia alguém poderoso ou alguém frágil, em uma perspectiva excludente, considerada na estrutura simbólica da relação médico-paciente, com dois postos a serem ocupados, por um e pelo outro, mesmo mantidas as suas autonomias.

Refletindo sobre as relações entre poder e conhecimento - tomando o poder como oposto à vulnerabilidade -, Foucault afirma que há uma relação entre poder e saber, e se apresenta ao nível do discurso (12). Para o autor, o fato de alguém portar e apresentar um conhecimento o elege à condição de poder em um dado meio que reconhece a essencialidade desse saber (12). Observa-se que, à medida em que não se conhece sobre um tema presente no diálogo, mais vulnerável se é. De fato, sob esse ponto de vista, pode- 
se afirmar que, em geral, a relação entre médicos e pacientes é assimétrica, no que se refere ao conhecimento (13).

Isso pode ser verificado no decurso do tempo, por meio da presença de poderes médicos diversos, que "se sobrepunham ao desconhecimento técnico dos pacientes acerca da medicina" (13). É que, também sob a noção foucaultiana, médicos, têm o "estatuto daqueles que têm o encargo de dizer o que funciona como verdadeiro" (12) na sociedade. Foucault se refere à sobreposição de poder das assertivas emanadas por médicos, que são transformadas em verdades na vida social sob a forma de discurso intelectual inicialmente inquestionável. Entretanto, em um cenário de ausência de assertividades, esse encargo não se perfaz, e tanto pacientes quanto médicos quedam-se em busca do tratamento e da cura, embora ainda se encontrem, simbolicamente, em locus de fragilidades peculiares aos sujeitos.

O contexto pandêmico passou a despontar, claramente, conjunturas atípicas. Episódios de desconhecimento médico global frente a um novo vírus e tratamento de sua doença, demonstrados em larga escala, descortinou a fragilidade e a vulnerabilidade da ciência, também susceptível a não saber, a se reconhecer desempoderada, ainda que temporariamente, e esta se mostrou incapaz de manifestar o típico conhecimento apto à resolutividade almejada.

Neste sentido, passou-se a notar, abruptamente, em pequenas ou grandes proporções, que há conjunturas idôneas a assemelhar médicos e pacientes: tanto a constatação de cenários que a ciência não alcança, não traduz, não responde ou soluciona, mostrando a medicina apta a descobrir-se susceptível; quanto a constatação de que médicos também são pessoas susceptíveis a adoecer, a sofrer estafas e a também frustrar-se diante da falibilidade da ciência médica.

\section{Falibilidade científica: quando não há soluções}

Em uma primeira vista, é possível a consideração da falibilidade como contexto errôneo, ou seja, em que se apresenta um desacerto na prática do profissional atuante daquele ramo científico, nesse caso, a medicina. Se assim fosse, considerar-se-ia, equivocadamente, que a falibilidade da ciência médica diz respeito aos erros eventualmente praticados por médicos, em condutas permeadas por culpa, seja por negligência, em que há displicência ou indiferença (14); por imprudência, denotando conduta precipitada ou 
imoderada (15); ou por imperícia, assinalando a prática de ato sem observância do que preceituam as normas técnicas (15).

A conduta culposa, em quaisquer dessas três hipóteses, seria apta a ensejar a responsabilização do profissional, portanto, o dever de indenizar, em caso de possuir nexo de causalidade com evento danoso junto ao paciente. Para tanto, ainda, seria preciso, ao médico, ter estado diante de possibilidades terapêuticas antes apresentadas pela literatura médica, em que pese, de todo o modo, continuar sob a sua responsabilidade a tentativa inafastável pela restauração da saúde fazendo uso do que puder dispor e estiver ao seu alcance.

O cenário pandêmico, em que há o desenvolvimento da doença COVID-19 e seu insucesso tratamentoso, até então oferece uma conjuntura em que a falibilidade pode se apresentar não por erro, mas por impossibilidade de estabelecimento de controle frente uma doença ainda não decifrada pelo saber. Pode-se denominar esse cenário de incontrolável, proveniente de uma situação grave e inevitável, logo, concernente à evolução patológica, em que a ciência médica, em seu estágio de desenvolvimento, não dispõe de meios para impedir. Portanto, decorrente de situação potencialmente incontornável, tendo em vista a ausência de certezas científicas e o progresso do quadro clínico (13).

Assim, têm-se uma conjuntura que não apresenta soluções, contudo, com o desenvolvimento futuro de pesquisas, pode vir a ser modificada e o conhecimento do campo de estudo pode passar a apontar para novas estratégias de intervenção e tratamento. Ou seja, uma ausência de restabelecimento da saúde em um tratamento médico de doença ainda pouco conhecida pela ciência, ainda que tendo o paciente sob seus cuidados por longo período, não enseja a percepção de imperícia, imprudência ou negligência médica e, por consequência, não enseja a sua responsabilização em uma perspectiva ético-jurídica. Afinal, somente se pode ser perito em um conhecimento já descrito pela literatura, passível de estudos cientificamente reconhecidos, em ações médicas cujos esforços tratamentosos, tal como afirmado, se faziam possíveis e disponíveis ao profissional.

Junto ao atual Código de Ética Médica brasileiro é possível notar-se essa compreensão, na medida em que afirma ser vedado ao médico "deixar de usar todos os meios disponíveis de promoção de saúde e de prevenção, diagnóstico e tratamento de doenças, cientificamente reconhecidos e a seu alcance, em favor do paciente." (16). Portanto, o insuficiente desenvolvimento da ciência em alguma área de abordagem e em 
determinado momento da história é capaz de levar à evolução incontrolável de um quadro patológico, não havendo que se falar em erro culpável do profissional médico.

Não deixa de haver, contudo, já em uma análise no que se refere à expectativa social de êxito, uma frustração diante deste cenário, o que também ocorre ao médico. Segundo o que refletem Silva e Teixeira, em análise ainda antecedente à conjuntura de pandemia, na sociedade a figura do médico é percebida como o principal estabelecedor da saúde, sendo entendido como sujeito com tamanha capacidade, revestido de um caráter quase mítico (17).

Deste ponto de vista é possível depreender-se, destarte, que ciente da prévia afirmação médica de enfrentamento de uma doença nova, cujas repercussões físicas e tratamentos ainda estão em vias de descoberta, é possível à sociedade frustrar-se, reconhecendo lacunas em um saber, agora insuficiente. Tomando os médicos como atores desta expectativa, e observando a sua formação acadêmica como também responsável por fazê-lo acreditar possuir qualidades quase sobre-humanas (17) há que se, também, analisar esse contexto de humanização dos dantes endeusados.

\section{Humanização médica: dor, estafa e frustração}

A humanização no atendimento médico, nas últimas décadas, têm sido um conceito trabalhado na perspectiva de incentivo à prática do cuidado aos pacientes, preconizando condutas que considerem seus sofrimentos e busquem reduzi-los a partir do anterior reconhecimento de seus corpos enquanto territórios humanos, portadores de dignidade, autonomia e respeito (18). Trata-se de um avanço, especialmente diante da tecnologização e cientificização da prática médica, que terminaram por inserir o risco da despersonalização das relações humanas tendo em vista o estímulo à percepção do corpo como legítimo território de investigação científica (19). Neste sentido, com a perspectiva de humanização da conduta passa-se à busca pelo reconhecimento da subjetividade, do sofrimento e da vulnerabilidade humana, a despeito de um espectro puramente biomédico da vida.

Junto a esse movimento, faz-se importante, ainda, a humanização do profissional de medicina, sob o aspecto da sua personificação, ou seja, do seu reconhecimento enquanto persona, corpo humano também apto ao sofrimento, a despeito da expectativa construída sobre a sua imagem enquanto ser inatingível. Trata-se de uma expectativa que compõe o espectro de confiança social na perspectiva tratamentosa em saúde (20), contudo, que pode ser refletida enquanto capaz de oportunizar, a essa mesma sociedade, a percepção de simetria, com o reconhecimento da vulnerabilidade da pessoa médica. 
No decurso da pandemia, entre as imagens veiculadas, quer seja em ambientes televisivos ou em redes sociais, capazes de descrever os cenários de busca por restabelecimento da saúde de pacientes portadores de COVID-19, estiveram as que retratam as faces arroxeadas dos profissionais médicos diante do uso prolongado de máscaras (21), entre outros equipamentos de proteção individual. Tratou-se de exposição incomum destes profissionais, com uma demonstração do cotidiano de exaustão física que contrasta com a inatingibilidade até então preconizada. Se, por um lado, essa demonstração frustra a expectativa que Ihes concede poderes sobre humanos, por outro lado proporciona o reconhecimento das suas vulnerabilidades na medida em que apresenta corpos também aptos à fragilização, portanto humanos, o que se opõe às características idôneas às representações de deuses (22).

A percepção de fragilização tem sido apresentada, ainda, em contextos de exaustão emocional, em que sentimentos como de se estar sobrecarregado e exaurido de recursos físicos e emocionais são percebidos por profissionais de saúde (23). Estudos têm demonstrado cenários como esse em unidades de saúde, especialmente aquelas relativas à terapia intensiva $(24,25)$, o que coincide com o vivenciado no decurso da pandemia, em que esse foi o locus de maior intensificação de busca pela restauração de quadros de COVID-19. Além disso, têm demonstrado que exposições prolongadas ao estresse sobretudo em busca de restauração da saúde diante de uma doença ainda a ser decifrada -, podem ser consideradas causas de esgotamento emocional, manifestadas por sensações de desamparo e derrotismo (26).

Neste cenário, porquanto há uma tendência à percepção de profissionais de medicina como revestidos de um poder apto a lhes fornecer prestígio, mas que também lhes cobra responsabilidades extremas, o contato com um contexto pandêmico pode mostrar-se como elemento de apresentação de fragilidades antes tamponadas. Trata-se de realidades limitadoras do ideal super-heróico, apto a frustrar o médico que se percebe impossibilitado de cumprir toda a demanda que lhe é apresentada, na forma que lhe é exigido, estando propenso a desenvolver sentimentos de angústia profunda (17).

Na continuidade deste raciocínio, conforme afirmam Silva e Teixeira relativamente a esse médico que percebe a limitação da sua ciência,

como seu status social desaprova a demonstração de sinais de dificuldade ou insegurança, o médico se proíbe de externalizar a angústia sentida, acabando por abafar seus sentimentos, sofrendo calado e isolado, 
construindo sua própria prisão, transformando-se em um ser que sofre, sem mostrar que sofre. (17)

Segundo esse ponto de vista, considerando que o perfil de endeusamento se legitima ao tempo em que são ocultados sentimentos humanos de sofrimento, à medida em que as faces arroxeadas e os relatos de exaustão foram significativamente expostos, no contexto pandêmico deu-se, assim, o início da modificação de uma representatividade até então de inatingibilidade, cujas consequências relacionais, positivas ou negativas, apenas em estudos específicos poderão ser avaliadas.

Conforme refletem Meirelles, Araújo Filho e Verdival,

vulneráveis são os médicos pela iminência da tomada de decisões referentes à uma doença desconhecida, vulneráveis são os demais profissionais da saúde, também expostos e exaustos pelo ritmo da rotina imposta pela pandemia, vulneráveis são os pacientes, em condições de comorbidades ou não, muitas vezes, sem acesso à saúde adequada, apavorados pelo potencial possibilidade de evolução negativa do seu quadro clínico. (27)

Portanto, nota-se o desconcerto quanto a dor, estafa e frustração de profissionais e pacientes, especialmente diante de panoramas em que é acrescida a falibilidade científica, quando não há soluções ou quando a luta pela vida se torna árdua. $E$, considerando todos os sujeitos envolvidos no cuidado, além do exposto quanto à vulnerabilidade e seus sentidos, é possível a ilação de um movimento significativo de simetralização e reconhecimento das susceptibilidades e fragilidades, amplamente.

\section{Aproximações e distanciamentos na assistência médica no contexto pandêmico}

Além de uma conjuntura de poucas assertividades científicas, entre as necessárias práticas assistenciais tanto aproximações subjetivas quanto distanciamentos físicos se fizeram presentes no atendimento médico a pacientes. É que, diante da impossibilidade de acompanhamento por familiares junto aos pacientes portadores de COVID-19, bem como dos prolongados tempos de internação, se conformaram, de algum modo, conjunturas propícias à priorização da comunicação pessoalizada.

A busca pela melhoria na perspectiva dialógica se tornou prioridade, e a comunicação e a humanização, já antes preconizados, se tornaram elementos fundamentais neste novo contexto, a exemplo do noticiado em que, em diversos países, buscando a pessoalização médicos realizaram impressão de fotografias de seus rostos e as colaram em seus uniformes para atender pacientes com coronavírus. $(28,29)$ 
Neste sentido, investimentos para a comunicação foram acrescidos na assistência, inclusive no que tange às notícias difíceis. Do mesmo modo, considerando as impossibilidades de atendimentos presenciais devido ao isolamento, esforços também se deram para a continuidade da assistência, de maneira que a telemedicina, antes pouco preconizada, se mostrou como uma significativa solução para a o distanciamento.

\section{Comunicação na assistência e protocolo Spikes}

No espectro do cuidado para a realização de comunicação, inclusive de notícias difíceis, adaptadas ao contexto do coronavírus, unidades de saúde passaram a apresentar protocolos e recomendações, que seguiram desde a avaliação de capacidade para comunicação verbal efetiva junto aos pacientes, a informação empática, a estes, sobre a proibição de visitação durante todo o internamento, sobre a possibilidade de intubação em caso de insuficiência respiratória e, ainda, sobre a demonstração de transparência e segurança a respeito da necessidade das condutas mesmo em momentos apavorantes para o doente que se percebe na iminência da morte (30).

Também assim, o protocolo Spikes, - eleito, para essa reflexão, em vista de sua substancial utilização atual nos centros de saúde brasileiros - que já vinha sendo aplicado em outros contextos, foi entendido como significativa estratégia para a comunicação no atendimento ao paciente com diagnóstico de COVID-19, preconizando fases de abordagem como a preparação para o encontro, a percepção subjetiva e clínica do paciente, o convite para o diálogo, a transmissão cuidadosa de informações considerando a possibilidade de expressão de emoções, e a finalização da comunicação com uma sumarização das informações esclarecidas e organização de estratégias clínicas. Cruz e Riera discorrem a respeito:

\footnotetext{
S - Setting up: Preparando-se para o encontro

Treinar antes é uma boa estratégia. Apesar de a notícia ser triste, é importante manter a calma, pois as informações dadas podem ajudar o paciente a planejar seu futuro. Procure por um lugar calmo e que permita que a conversa seja particular. Mantenha um acompanhante com seu paciente, isso costuma deixá-lo mais seguro. Sente-se e procure não ter objetos entre você e seu paciente. Escute atentamente o que o paciente diz e mostre atenção e carinho.

$P$ - Perception: Percebendo o paciente

Investigue o que o paciente já sabe do que está acontecendo. Procure usar perguntas abertas.

I - Invitation: Convidando para o diálogo

Identifique até onde o paciente quer saber do que está acontecendo, se quer ser totalmente informado ou se prefere que um familiar tome as decisões por
} 


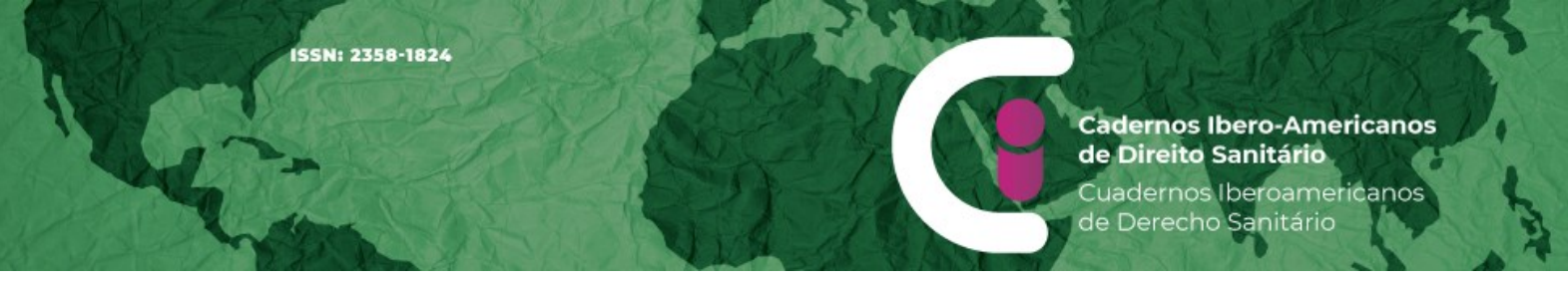

ele. Isso acontece! Se o paciente deixar claro que não quer saber detalhes, mantenha-se disponível para conversar no momento que ele quiser.

$\mathrm{K}$ - Knowledge: Transmitindo as informações

Introduções como "infelizmente não trago boas notícias" podem ser um bom começo. Use sempre palavras adequadas ao vocabulário do paciente. Use frases curtas e pergunte, com certa frequência, como o paciente está e o que está entendendo. Se o prognóstico for muito ruim, evite termos como "não há mais nada que possamos fazer". Sempre deve existir um plano!

E - Emotions: Expressando emoções

Aguarde a resposta emocional que pode vir, dê tempo ao paciente, ele pode chorar, ficar em silêncio, em choque. Aguarde e mostre compreensão. Mantenha sempre uma postura empática.

S - Strategy and Summary: Resumindo e organizando estratégias

É importante deixar claro para o paciente que ele não será abandonado, que existe um plano ou tratamento, curativo ou não. (31)

Neste rumo, trata-se de um protocolo que tem a comunicação a partir da pretensão de abarcar o que o paciente precisa saber, de forma apropriada, preocupando-se com sua reação afetiva e com a retenção da informação (31). No cenário do tratamento para a COVID-19, da mesma forma, essa atenção se fez presente, de modo que recomendações para a comunicação com estes pacientes, especificamente, passaram a ser veiculadas por gestores, a exemplo das relativas aos cuidados paliativos publicadas pela Secretaria de Saúde do Governo do Estado da Bahia, no Brasil:

Lista de checagem - Compartilhando Más Notícias

1-Encontre um local apropriado e tempo adequado. Garanta conforto, privacidade e silêncio e ausência de interrupções.

2-Prepare-se a si mesmo, recapitule pontos chaves e observe suas reações pessoais.

3-Considere o envolvimento da família, especialmente nas questões decisivas e outros profissionais de saúde. Pergunte ao paciente quem deveria estar presente. No hospital, inclua um enfermeiro e psicólogo. A menos que a conversação ocorra no contexto de uma relação bem estabelecida, comece por "sentir" o paciente e a família. O que o paciente e a família sabem? O que eles desejam saber? Permita-os fazerem perguntas e absorverem as informações aos seus próprios modos. Procure entender a perspectiva do paciente e ou família.

4-Ouça. Atender ao paciente é frequentemente mais importante do que o que você diz. Ouça e responda às preocupações e emoções. Aceite o silêncio. Estimule perguntas. Clarifique. O que é "esperança" para este paciente?

5-Seja breve e simples, dando uma mensagem chave em poucas sentenças. Dê explicações plenas e claras no jargão de uma linguagem livre. Esteja atento a eufemismos. Repita pontos chaves e sublinhe-os.

6-Coloque objetivos realísticos para a discussão inicial, evitando sobrecarga de informação. Entenda que más notícias são um processo, não um evento. Adapte a informação ao ouvinte. Exposição gradual para assuntos difíceis. Mantenha em mente objetivos chaves: o que realmente o paciente precisa saber? 
7-Seja honesto e fale de maneira firme e franca. Evite falso otimismo e falsa confiança, mas também excesso de desencorajamento. Respeite preferências pessoais e culturais ao compartilhar informações. Evite falsas certezas ou exatidões, mas atenda às necessidades do paciente com relação à informação prognóstica.

8-Responda com afeto. Aja ativamente e encoraje relações emocionais. Seja companheiro. Tenha empatia. Reconheça dificuldades. Transmita seu cuidado. Identifique apoios atuais e ofereça recursos adicionais.

9-Ofereça os próximos passos que conduzam uma atenção continuada. Planeje um seguimento para compartilhar informação, resolver dúvidas e apoiar. Garanta disponibilidade e atenção continuada.

10- Documente a informação compartilhada e comunique sobre isto para a equipe dos cuidados de saúde. (32)

Compreende-se, assim, pela significativa ocorrência de esforços em se organizar contextos de cuidado na comunicação aos pacientes, entre eles os diagnosticados com COVID-19. Assim, aos pacientes fisicamente próximos se fez possível essa abordagem. Quanto àqueles em distanciamento social, a telemedicina se mostrou uma importante ferramenta, conforme se observará a seguir.

\section{Telemedicina como recurso para a o distanciamento na assistência}

Medidas preventivas em busca da não propagação do vírus favoreceram ao atendimento na assistência mediado pela tecnologia, a chamada telemedicina, em formatos antes não preconizados explicitamente pelas normativas médicas brasileiras. Isto porque a Resolução CFM n 1.643, presente desde 2002, que define e disciplina a prestação de serviços através da telemedicina, a conceitua "como o exercício da Medicina através da utilização de metodologias interativas de comunicação audiovisual e de dados, com o objetivo de assistência, educação e pesquisa em Saúde" (33) contudo, não especifica formas de prestação deste serviço, não abordando claramente, por exemplo, a possibilidade de atendimento em que médicos e pacientes encontram-se em locais diversos, sem que estes tenham, fisicamente, ao seu lado, profissionais de saúde em amparo. De todo o modo, abordou a responsabilidade profissional do atendimento, informando caber esta ao médico assistente do paciente e ressalta: "os demais envolvidos responderão solidariamente na proporção em que contribuírem por eventual dano ao mesmo." (33)

No decurso da pandemia se fez necessário a utilização da telemedicina de imediato e, para resguardo do contexto ético, alguns Conselhos Regionais de Medicina publicaram também resoluções dispondo sobre essa assistência especificamente durante o estado de calamidade pública, reconhecida, no Brasil, pelo Decreto Legislativo n 6/2020 (34), que determina isolamento, quarentena e distanciamento social, a exemplo da Resolução 


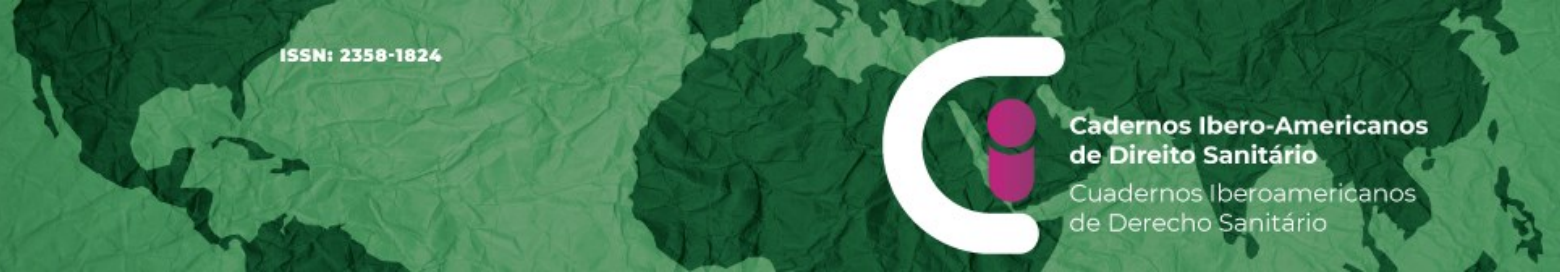

CREMEB n 367/2020 (35). Essa norma esmiuçou cinco modalidades de telemedicina e telessaúde, abarcando conceitos de teleorientação, telemonitoramento, teleinterconsulta, teleconsulta e teleconsulta hospitalar:

Art. $3^{\circ}$ Constituem as modalidades de telemedicina e telessaúde acima
mencionadas:
$\S 1^{\circ}$ Teleorientação, permite que profissionais da medicina realizem à
distância a orientação e o encaminhamento de pacientes em distanciamento
social.
$\S 2^{\circ}$ Telemonitoramento, permite a realização de ato sob orientação e
supervisão médica para monitoramento ou vigilância à distância de
parâmetros de saúde e/ou doença.
$\S 3^{\circ}$ Teleinterconsulta, permitida exclusivamente para troca de informações e
opiniões entre médicos, para auxílio diagnóstico ou terapêutico.
$\S 4^{\circ}$ Teleconsulta, permitida a consulta do paciente, com a possibilidade de
prescrição por parte do médico de tratamento, solicitação de exames ou
outros procedimentos, sem o exame direto do paciente.
$\S 5^{\circ}$ Teleconsulta hospitalar, permitida quando o médico e pacientes estão
dentro do mesmo serviço de saúde e o médico, por restrições justificáveis de
realizar o exame direto do paciente, acessa o prontuário, obtém informações
a partir de outros médicos e profissionais de saúde, e, eventualmente se
comunica com o paciente a distância e, a partir destes dados, faz registros,
emite relatórios, solicita exames e prescreve medicamentos e procedimentos. (35)

No que se refere à legislação brasileira erga omnes, a Lei n 13.989/2020 dispôs sobre o uso da telemedicina durante a crise causada pelo coronavírus (SARS-CoV-2), determinando, em seu artigo $4^{\circ}$, que "o médico deverá informar ao paciente todas as limitações inerentes ao uso da telemedicina, tendo em vista a impossibilidade de realização de exame físico durante a consulta". (36) Também assim, normativas ministeriais de saúde dispuseram sobre a prática de telemedicina em caráter temporário e excepcional, especificamente a Portaria $n^{\circ} 467 / 2020$.

Em seu artigo $2^{\circ}$ a norma afirma que

as ações de Telemedicina de interação à distância podem contemplar o atendimento pré-clínico, de suporte assistencial, de consulta, monitoramento e diagnóstico, por meio de tecnologia da informação e comunicação, no âmbito do SUS, bem como na saúde suplementar e privada. (37)

Em decorrência, em seu artigo $3^{\circ}$, parágrafo único, inciso I, traz que os médicos deverão: "atender aos preceitos éticos de beneficência, não-maleficência, sigilo das informações e autonomia" (37).

Importante a menção a princípios bioéticos neste documento, o que reforça a aplicabilidade da Declaração Universal sobre Bioética e Direitos Humanos na prática do 
cuidado da saúde no Brasil. Em seu artigo 5ª a Declaração traz o princípio "Autonomia e Responsabilidade Individual", e afirma que

deve ser respeitada a autonomia dos indivíduos para tomar decisões, quando possam ser responsáveis por essas decisões e respeitem a autonomia dos demais. Devem ser tomadas medidas especiais para proteger direitos e interesses dos indivíduos não capazes de exercer autonomia. (4)

Logo em seguida, a Declaração traz, em seu artigo $8^{\circ}$, a abordagem tanto sobre a vulnerabilidade, quanto sobre a integridade individual, afirmando que "indivíduos e grupos de vulnerabilidade específica devem ser protegidos e a integridade individual de cada um deve ser respeitada" (4).

Focando nos sujeitos da relação médico-paciente, convém relembrar, nesta mesma perspectiva, que é a partir do termo em latim integritas que a palavra integridade provém, o que atribui, a si, os significados como inteireza, pureza e inalterabilidade (38). Segundo Hermeren, trata-se de um estado de inteireza que demanda respeito tanto em nível físico, tomando o corpo de um sujeito como território que lhe pertence e que não pode ser invadido senão com sua autorização prévia, quanto em nível mental, exigindo o respeito às crenças e valores, o que não comporta qualquer ridicularização ou desprezo (38). Neste segundo aspecto, ponderando também a estrutura da relação médico-paciente, ambos, igualmente, têm estimada a sua inteireza, especialmente se mantido, como cenário, o respeito aos seus territórios, considerados corpos e mentes.

Assim, em atenção ao respeito às integridades, e retomando a reflexão sobre a comunicação, agora sob o aspecto do atendimento à distância, segundo Gonçalves Junior et al é possível a ocorrência de adaptações ao protocolo Spikes no contexto da telemedicina. Para os autores, no decurso da pandemia pela COVID-19 os profissionais têm sido obrigados a transmitir notícias, inclusive más notícias, e as conversas por meio de sistemas de comunicação online passaram a ter um papel cada vez mais importante, inclusive nos cuidados paliativos. E como esses serviços online tendem a desafiar a comunicação eficaz e a comunicação de más notícias, se tornam essenciais os usos de ferramentas, como o protocolo Spikes, em busca da operacionalização do atendimento e preparação dos profissionais para uma abordagem mais acolhedora, eficaz e menos impactante (39). Para tanto, os autores sugerem uma adaptação do protocolo Spikes no manejo de pacientes hospitalizados com COVID-19 quando as intervenções terapêuticas são limitadas, com o objetivo de reduzir o sofrimento psíquico do profissional de saúde e fomentar a discussão e 
melhoria da comunicação assertiva no ambiente terminal devido à pandemia de COVID-19 (39).

\section{Considerações finais}

A partir da análise da relação médico-paciente na assistência em contexto pandêmico reflete-se ser possível descortinar-se vulnerabilidades de médicos e pacientes, estas que já as apresentavam em diversos sentidos. Acrescidos ao habitualmente visto na assistência, o contexto pandêmico apresentou as fragilidades da ciência e dos médicos, tornando nítida a possibilidade de simetralização da relação médico-paciente a partir da humanização, não somente do atendimento, mas da imagem do profissional de saúde antes endeusado, embora tenha sido mantida a expectativa e admiração social.

Trata-se da possibilidade de simetria na relação em contexto de falibilidade da ciência e percepção da vulnerabilidade médica, seja por, aparentemente, não haver soluções imediatas aos contextos patológicos ou respostas prontas quanto aos seus prognósticos, seja pela constatação de que médicos são humanos, capazes de sentir dor, estafa e frustração.

Da mesma forma, a análise da relação no decurso da pandemia mostrou-se favorável à percepção das possibilidades de aproximações e distanciamentos entre médicos e pacientes, seja pela via da comunicação presencial, com o acréscimo de recomendações e protocolos aos profissionais de saúde, a exemplo do protocolo Spikes, seja por meio da telemedicina, disposta enquanto significativo recurso para a o distanciamento na assistência.

Nestas conjunturas, é possível considerar-se, por fim, que decorreram efetivas possibilidades de modificações no perfil da prática assistencial em medicina no contexto pandêmico da COVID-19, cujas consequências relacionais, positivas ou negativas, apenas em estudos específicos poderão ser avaliadas. De todo o modo, avanços significativos se fizeram presentes, especialmente nas esferas da aproximação dos sujeitos e possibilitação de simetralização de uma relação, até então praticada com ocultação dos sentimentos humanos de sofrimento médico, com modificação em busca da efetiva comunicação e redução de uma representatividade até então de inatingibilidade.

\section{Referências}

1. Sontag S. Doença como metáfora, AIDS e suas metáforas. São Paulo: Companhia das Letras; 2007. p. 11. 
2. Canguilhem G. Escritos sobre a medicina. Tradução Vera Avellar Ribeiro. Rio de Janeiro: Forense Universitária; 2005.

3. Patrão Neves M. Sentidos da vulnerabilidade: característica, condição, princípio. Revista Brasileira de Bioética. 2006;2(2):157-172.

4. UNESCO. Declaração Universal sobre Bioética e Direitos Humanos. [citado em 01 mar. 2021]. Disponível em:

http://bvsms.saude.gov.br/bvs/publicacoes/declaracao univ bioetica dir hum.pdf

5. Lorenzo C. Los instrumentos normativos em ética de la investigación em seres humanos em América Latina: análisis de su potencial eficácia. In: Keyeux G, Penchaszadeh VE, Saada A. Ética de la Investigación en seres humanos y políticas de salud pública. Bogotá: UNESCO-Unibiblos; 2006. 167-90.

6. Garrafa V, Prado MM. Mudanças na Declaração de Helsinki: fundamentalismo econômico, imperialismo ético e controle social. Cadernos de Saúde Pública. 2001;17:1489-1496.

7. Correa FJL. Pobreza, vulnerabilidad y calidad de vida en América Latina. Retos para la Bioética. Acta Bioethica. 2011;17(1):19-29.

8. Kant I. Fundamentação da metafísica dos costumes e outros escritos. Tradução Leopoldo Holzbach. São Paulo: Editora Martin Claret; 2005. p. 85.

9. Anjos MF. A vulnerabilidade como parceira da autonomia. Revista Brasileira de Bioética. 2006;2(2):173-86.

10. Kemp P, Rendtorff JD. Princípio de vulnerabilidade, Nova enciclopédia da Bioética: medicina, ambiente, tecnologia. p. 688.

11. Renaud M. Solicitude e vulnerabilidade. In: Carvalho AS, coordenadora. Bioética e vulnerabilidade. Coimbra: Edições Almedina; 2008. p. 11-20.

12. Foucault M. Microfísica do poder. Organização e tradução Roberto Machado. Rio de Janeiro: Edições Graal; 1979.

13. Vasconcelos C. Direito médico e Bioética: história e judicialização da relação médicopaciente. Lumen Juris: Rio de Janeiro; 2020.

14. Castro JM. Responsabilidade civil do médico. São Paulo: Método; 2005.

15. Vasconcelos C. Responsabilidade médica e judicialização na relação médico-paciente. Rev bioét (Impr.). 2012;20(3):389-96.

16. Brasil. Conselho Federal de Medicina do Brasil. Resolução CFM n 2.217/2018. Aprova o Código de Ética Médica. Publicada no D.O.U. de 01 de novembro de 2018, Seção I, p.179. [citado em 01 mar. 2021]. Disponível em:

https://sistemas.cfm.org.br/normas/visualizar/resolucoes/BR/2018/2217 


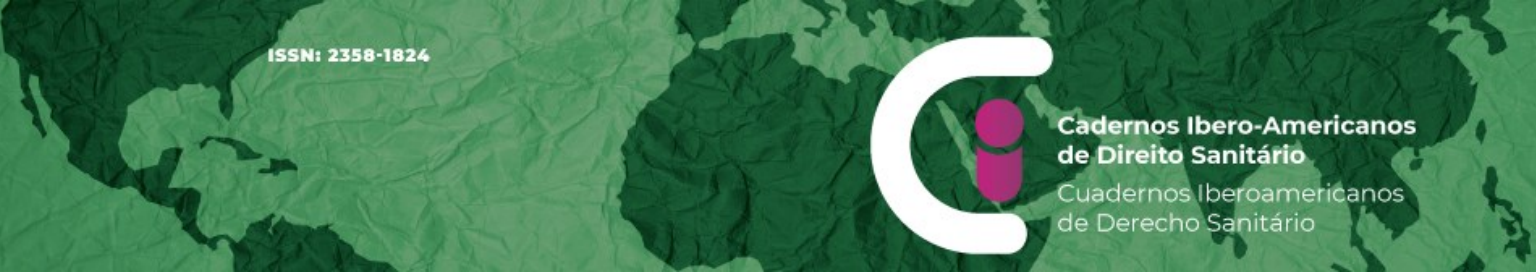

Disponível em: http://www.scielo.br/scielo.php?script=sci arttext\&pid=S010412902018000300809\&lng=en doi: https://doi.org/10.1590/s0104-12902018180007

27. Meirelles AT, Araújo Filho JE, Verdival R. Vulnerabilidade, Médicos e Pandemia. CVMed - Direito Médico Comentado. 05 jan. 2021 [citado em 01 mar. 2021]. Disponível em: http://cvmed.com.br/2021/01/05/vulnerabilidade-medicos-e-pandemia/

28. Tuchlinski C. Médicos imprimem fotos de seus rostos e colam em uniforme para atender pacientes com coronavírus. O Estado de S.Paulo [Internet]. 13 abr. 2020 [citado em 01 mar. 2021]. Disponível em:

https://emais.estadao.com.br/noticias/comportamento, medicos-imprimem-fotos-de-seusrostos-e-colam-em-uniforme-para-atender-pacientes-com-coronavirus, 70003269015

29. Tribuna de Jundiaí. Para tranquilizar pacientes com coronavírus, médicos e enfermeiros colam fotos de seus rostos em uniforme: O movimento que começou nos Estados Unidos chegou em pouco tempo ao Brasil; agora, profissionais de saúde brasileiros também adotaram a iniciativa. Tribuna de Jundiaí. 14 abr. 2020. [citado em 01 mar. 2021]. Disponível em https://tribunadejundiai.com.br/saude/coronavirus/paratranquilizar-pacientes-com-coronavirus-medicos-e-enfermeiros-colam-fotos-de-seus-rostosem-uniforme/

30. Universidade Federal de Alagoas. Hospital Universitário Professor Alberto Antunes. Recomendações para comunicação de notícias difíceis adaptadas ao contexto do coronavírus 2019 (covid 19) no HUPAA-UFAL/EBSERH. 24 abr. 2020. [citado em 01 mar. 2021]. Disponível em: http://www2.ebserh.gov.br/documents/221436/5552546/POP_Recomenda\%C3\%A7\%C3\%B5es-Comunica\%C3\%A7\%C3\%A30-Dif\%C3\%ADcil-COVID19.pdf/f5617f5c-705a-4748-85c5-9c3a0c3f6edc

31. Cruz CO, Riera R. Comunicando más notícias: o protocolo SPIKES. Diagn Tratamento [Internet]. 2016 [citado em 01 mar. 2021];21(3):106-8. Disponível em:

https://docs.bvsalud.org/biblioref/2016/08/1365/rdt v21n3 106-108.pdf

32. Santos FS, Apolônia K. Listas de checagem para evolução clínica, comunicação, conferência familiar e deliberação Bioética em cuidados paliativos/covid-19 da SESAB. Governo do estado da Bahia, Secretaria de Saúde. [citado em 14 mar. 2021]. Disponível em: http://www.saude.ba.gov.br/wp-content/uploads/2020/05/LISTA-DE-CHECAGEM.pdf

33. Brasil Conselho Federal de Medicina. Resolução CFM n 1.643/2002. Publicada no D.O.U. de 26 de agosto de 2002, Seção I, p. 205. [citado em 01 mar. 2021]. Disponível em: https://sistemas.cfm.org.br/normas/visualizar/resolucoes/BR/2002/1643

34. Brasil. Decreto Legislativo $n^{\circ}$ 6/2020. Reconhece, para os fins do art. 65 da Lei Complementar $n^{\circ} 101$, de 4 de maio de 2000, a ocorrência do estado de calamidade pública, nos termos da solicitação do Presidente da República encaminhada por meio da Mensagem n 93, de 18 de março de 2020. DOU de 20.3.2019 - Edição extra C. [citado em 01 mar. 2021]. Disponível em: http://www.planalto.gov.br/ccivil 03/portaria/DLG62020.htm\#: :text=DECRETO \%20LEGISLATIVO\%20N\%C2\%BA\%206\%2C\%20DE, 18\%20d e\%20mar\%C3\%A7o\%20de\%202020 
